\title{
DEVELOPING THE LANGUAGE PRAGMATIC COMPETENCE IN CHILDREN WITH MODERATE AND SEVERE MENTAL DISORDERS
}

\author{
Dina Bethere \\ Liepaja University, Latvia \\ Inese Roste - Plostniece \\ Liepaja Special boarding school, Latvia \\ Kaiva Žīmante \\ Liepaja Special boarding school, Latvia
}

\begin{abstract}
In this research the effectiveness of didactic system is analysed in relation to forming communicative competence of children with moderate and severe mental disorders (MSMD) in the older classes. This publication presents the language competency model, which in this research serves as a theoretical base for studying the language development of pupils and for pedagogical activity. The publication reveals the system of methodological approaches in the educational process for developing pragmatic language competency for pupils with MSMD.
\end{abstract}

Keywords: didactic approaches, pragmatic competency, pupils with mental disorders, language competency.

\section{Introduction}

Acquisition of linguistic competence for children with MSMD is linked to many challenges. In this regard, one of the main challenges is lack of common definition for this phenomenon. Language competence is a complex theoretical construct. In general it includes the productive and receptive abilities to manage the language components, e. g., grammatical features and vocabulary, and skills to use them in communication situations (Field, 2004).

The other challenge is connected with the difficulty to research the set of previously characterized abilities and skills because of the subtle differences and expectations that might exist in specific situations, cultures, and learning contexts. However, it can be estimated by speech intelligibility, developmental speech - language milestones, listening skills, and language comprehension (Smith \& Cascella, 2007).

With the respect to above mentioned conditions, the language competence of children with MSMD is considered as particularly complicated research sphere. In this context the challenge is the individually-specific development potential, which is characteristic to the members of this marginal group. In the research process one must take into account the limitations of (a) intellectual abilities, (b) collection of conceptual, social and practical adaptive skills, (c) participation, interaction and social roles, (d) complete physical, mental and 
social well-being, (e) interrelated conditions within every child lives, his own everyday life and includes the immediate social settings (Petry \& Maes, 2007).

These conditions of development and use of the social context consequently affect the language development of this marginal group of children. The limitations can be observed in various expressions, which include both quantity and quality deficiencies of vocabulary, and in some cases absolute deficit of expressive verbal speech. At the same time these cases are also characterized by poor ability and skills to organize the language components in a meaningful phrase.

On the other hand, the main aim of the educational system for children with mental disorders is potentially more successful individual socialization process, and particularly the language competence is regarded as the foundation of this process. Keeping in mind the personality traits of pupils with MSMD, the acquisition of their language competence is focused on obtaining the knowledge and skills necessary for life in the society. Therefore, the most important aspect of language development is neither pure pronunciation nor absolutely infallible grammar, but it is to be understood as an integrated component of a successful personality development (Lentes \& Thiesen, 2007), which would compensate the gaps of psychic functions and facilitate the acquisition of social roles and integration in different social contexts. Thus, obtaining the language pragmatic competence is one of the main tasks for children with MSMD.

This publication is part of the wider research study which aims to elaborate the functional methodical approach system for developing language pragmatic competence for children with MSMD. This publication examines language development regularities, research methodology and pedagogical activity methodology for above mentioned group of children. Selected language competence development profiles of children with severe mental disorders have been used for revealing the research results.

\section{Language competence model for children with MSMD}

As previously indicated, pupils with MSMD have individual-specific resources for their general language system development. Publication authors' experience proves that these cases are characterized by delayed language development. Sometimes expressive language impacts the severe damages of central nervous system. The lack of verbal means of communication is offset with gestures, confusing sounds, peculiar words in which children place their own meaning. In addition, the deficit of language skills limits also the updating, modification and enrichment of the information flow, while communication partners are in mutually active process. At the same time, orientation in communicative tasks and understanding of communication situations is limited as well (Smith \& Cascella, 2007). 
Therefore, in order to ground the effective communicative skill development research of children with MSMD, the complex language competency model is needed. This model must ensure systematic research of each particular child's language skills in all its variety and in correlations with possible deficits. At the same time it must be useful for activation and further development of language abilities and skills for children with mental disorders. For these reasons the Bachman \& Palmer's (2010) model of language ability is very useful, which is also undoubtedly multidisciplinary and complex in its nature. A major advancement of this model in comparison to the previous ones seems to be its emphasis on the central role of strategic competence, metacognitive strategies or higher order processes that explain the interaction of knowledge and affective components of language use (Bachman \& Palmer, 1996, 2010; Fulcher \& Davidson 2007). The previously characterized language competence model includes several interrelated competencies.

Table 1. Model of Language Competence

\begin{tabular}{|l|l|l|l|}
\hline \multicolumn{4}{|c|}{ Language Competence } \\
\hline Organizational Competence & Pragmatic Competence \\
\hline \multicolumn{4}{|c|}{ Vocabulary/Lexicon/Semantics } \\
\hline Grammatical & Textual & Illocutionary & Sociolinguistic \\
Competence & Competence & Competence & Competence \\
\hline Morphology & Discourse & Problem solving & Dialect \\
Syntax & Coherency & Ideas & Register \\
Phonology & Rhetoric & Imagination & Naturality \\
& & Manipulation & Culture \\
\hline
\end{tabular}

Model is based on: Bachman \& Palmer 1996; Reichert-Garschhammer \& Kieferle, 2011.

Generally describing the above mentioned language competence subcomponents, it should be noted, that the indicators of grammatical competence are extensive vocabulary and its phonematic structure, and skills to apply the features of morphology and syntax, which cumulates in formation of meaningful and formally correct sentences. It can be added that in the verbal language of children with MSMD the limitations can be observed in several essential components including (a) oral language and vocabulary, (b) phonological awareness, (c) phonics and word recognition, (d) fluency, and (e) comprehension (Allor et all., 2008; Hudson at all., 2013; Lemons et all., 2012; Stockall, 2011).

Consequently, these limitations influence the textual competence, which includes skills to use appropriate means and their elements for creating an oral or written text. In this regard children with mental disorders often experience difficulty of planning (e.g., retrieving and organizing content knowledge and writing for audience), producing text (e.g. constructing sentences beyond a reiteration of listing topical knowledge), and effectively revising compositions 
with regard to the organization of ideas and content (Woods-Groves at all., 2014, 249).

In order to diminish the above mentioned deficits, for these children the augmentative and alternative communication systems often provide the means by which they can communicate with other individuals in their lives (Beck et all., 2008; Beecher \& Childre, 2012). In this case for achieving didactic goals the following global symbols are used: drawings, diagrams, pictograms, as well as depictions of operational and behavioural models. The effects of a use of comprehensive sign language are (a) sight word knowledge, (b) letter recognition, (c) letter-sound knowledge, (d) vocabulary, (e) listening comprehension (Beecher \& Childre, 2012).

Pragmatic competence includes skills that ensure language use is the social context. Accordingly, the illocutionary competence allows expressing ideas, knowledge and feelings, manipulating with surrounding environment, using metaphors, humouring and understanding the poetic texts. The sociolinguistic competence provides with possibilities to use the means of language according to the particular context of social environment. This research study focuses on challenges and achievements of pragmatic aspect perfection of language competence.

\section{Research design}

\section{Participants}

The participants of the research: 13 pupils of special educational institution, age of 15-16, and five qualified special education teachers.

Forming the group of research participants the most characteristic factors that influence their individual development were summarized: age, special needs (official diagnosis), social conditions (lives in the family or social care centre), educational history (study year, change of education programme), use of language skills.

Two rather different cases are used for describing the research results

Table 2. The context of pupils' development

\begin{tabular}{|l|l|c|c|c|}
\hline Participants & $\begin{array}{c}\text { Age/ } \\
\text { Gender }\end{array}$ & Special Needs & Social conditions & Education history \\
\hline PP1 & $16 / \mathrm{M}$ & $\begin{array}{c}\text { Severe mental } \\
\text { development } \\
\text { disorder, cerebral } \\
\text { palsy }\end{array}$ & $\begin{array}{c}\text { Lives in the care } \\
\text { centre }\end{array}$ & $\begin{array}{c}\text { 8th study year, } \\
\text { education programme } \\
\text { has not been changed }\end{array}$ \\
\hline PP2 & $16 / \mathrm{M}$ & $\begin{array}{c}\text { Severe mental } \\
\text { development } \\
\text { disorder, Down } \\
\text { syndrome }\end{array}$ & $\begin{array}{c}\text { Lives together with } \\
\text { family, in working } \\
\text { days stays in a } \\
\text { boarding school }\end{array}$ & $\begin{array}{c}\text { 8th study year, } \\
\text { education programme } \\
\text { has not been changed }\end{array}$ \\
\hline
\end{tabular}


Significant differences can be observed in organizational competence profiles in the beginning of the research.

Tabele 3. Organizational Competence profiles at the beginning of the research

\begin{tabular}{|c|c|c|c|}
\hline $\begin{array}{c}\text { Partici- } \\
\text { pants }\end{array}$ & Vocabulary/Lexicon & $\begin{array}{c}\text { Grammatical } \\
\text { Competence }\end{array}$ & Textual Competence \\
\hline PP1 & $\begin{array}{c}\text { Incommunication } \\
\text { does not use verbal } \\
\text { language }\end{array}$ & $\begin{array}{c}\text { Uses alternative } \\
\text { means of } \\
\text { communication }\end{array}$ & $\begin{array}{c}\text { Respond to the simple } \\
\text { questions about family and } \\
\text { daily routine, using } \\
\text { alternative means }\end{array}$ \\
\hline PP2 & $\begin{array}{c}\text { Incommunication } \\
\text { uses verbal language, } \\
\text { uses it according to } \\
\text { the situation and } \\
\text { according to the } \\
\text { emotional state }\end{array}$ & $\begin{array}{c}\text { Uses verbal and } \\
\text { alternative means of } \\
\text { communication; } \\
\text { according to situation } \\
\text { understands and can } \\
\text { answer simple } \\
\text { questions, name } \\
\text { objects and activities, } \\
\text { in conversation uses } \\
\text { nouns and verbs }\end{array}$ & $\begin{array}{c}\text { Can answer simple questions } \\
\text { about his family, create a story } \\
\text { about himself, family; if } \\
\text { leading questions are asked, } \\
\text { can clearly tell about his } \\
\text { experiences, and answer } \\
\text { questions about particular } \\
\text { situations. }\end{array}$ \\
\hline
\end{tabular}

\section{Research method and procedure}

This research was conducted in year 2012-2014 in special primary education establishment with 23 years of experience on implementation of special education programmes for pupils with MSMD.

In the research programme three interrelated and successive phases can be distinguished. In the first phase, analysing 123 case studies, the typical language development expressions were researched for children with severe mental disorders. Their differentiation has served as the basis for elaboration of 83 typical indicator system of language competence.

In the second phase of the study the observation of the various educational process routines took place for children with severe mental disorders with the aim to explore the functionality of previously acquired indicators and their compliance with the actual cases.

In the third phase of the study the pedagogic approach system has been used for developing the language competence, including the pragmatic competence. For noticing the changes in the language competence structure, the observation of pupils' development was performed repeatedly in this phase. The research process was taking place 10 months, mainly in learning situations in classrooms, in groups and individually, and in the after-school activities. The research process and results are revealed in observation protocols.

\section{Intervention}

In the language learning process the role play is the way to prepare students for different life situations, where language elements are means of resolving the 
situations. Using this method, students have opportunities to observe and understand a variety of communicative situations and social roles. The content of role plays is composed by pupils or their teachers depending on individual development potential of each pupil.

Communication situation modelling contributes to the development of students' understanding of the factors influencing communication. In this context, students are provided with opportunities to explore different possible situations in connection with various tasks that need to be performed in communication process.

The interview is used to develop students' skills of formulating questions and answers. In the intervention period methodological guidelines have been developed for using this approach: (1) teacher elaborates the question system and develop it further together with the pupils, (2) the teacher agrees with pupils who will be the respondent in the interview, (3) the implementation process of the interview is associated with the role play,e.g., taking the role ofjournalist or TV news presenter, (4) depending on the writing skills of the interviewer, the respondent's answers are fixed in writing or tape-recorded, (5) the narrative, prepared together with teacher on the basis of responses acquired in the interviews, is presented to the class members.

Dialogue and its formation in the intervention period has been used for revealing the problem issues in both daily and learning situations. It must be admitted that forming a sensible and continuous dialogue for students with MSMD is a complex process. Using this technique, the skill to observe other people's communication process is of great importance in order to perceive the information expressed in it. Therefore, it is necessary to analyse the dialogue conversation together with the teacher, understanding its nature and main aspects.

The aim of situation plays is to develop specific life situation awareness. The use of this methodological approach served as the basis of language pragmatic competence development in several aspects: (a) to support use of meaningful language components in various daily situations, as well as in social and cultural activities, (b) to develop skill to implement various communicative tasks with language resources and orientate in different communication situations (c) to encourage to overcome possible insecurity before starting communication with people one knows and with the strangers, (d) to improve the understanding of communicative culture. Implementing this methodological approach, pupils are encouraged to act in accordance with oneself, one's own experience and feelings. Thus, the goals of communicative situations are determined by the students themselves. However, teacher's support is important in this process according to the individual needs of pupils.

In intervention period, the methodological approaches for strengthening the acquired skills are used to ensure that the acquired pragmatic language skills are applied in real life situations, to promote pupils' interest about them and to 
initiate future learning process. For these purposes the study tours and visits to cultural, sports and other events are used, observed and assessed.

It can be added that events with a transparent thematic content and in a limited space, such as concerts or theatre performances, or watching together a TV programme or listening to fairy tales in out-of-school hours are considered as effective for training the language pragmatic competence.

\section{Results}

In the end of the intervention period, the repeated observation of research participants was conducted with the aim to explore the qualitative and quantitative changes of children's linguistic competence.

Table 4. The quantitative indicators of changes in pupils'linguistic competence

\begin{tabular}{|c|c|c|c|c|c|c|c|c|}
\hline \multirow[b]{2}{*}{ 总 } & \multicolumn{2}{|c|}{$\begin{array}{l}\text { Grammatical } \\
\text { Competence }\end{array}$} & \multicolumn{2}{|c|}{$\begin{array}{c}\text { Textual } \\
\text { Competence }\end{array}$} & \multicolumn{2}{|c|}{$\begin{array}{l}\text { Illocutionary } \\
\text { Competence }\end{array}$} & \multicolumn{2}{|c|}{$\begin{array}{l}\text { Sociolinguistic } \\
\text { Competence }\end{array}$} \\
\hline & 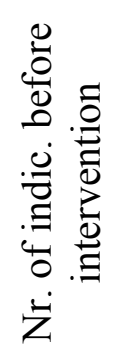 & 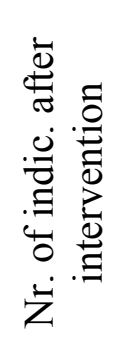 & 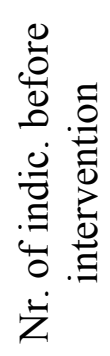 & 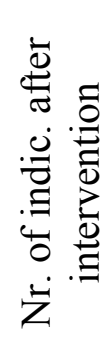 & 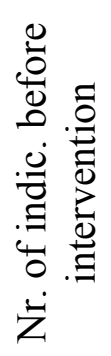 & 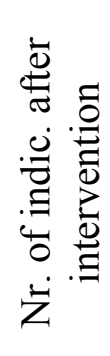 & 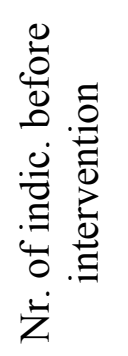 & 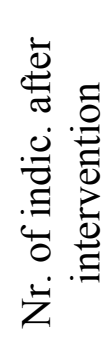 \\
\hline PP1 & 1 & 1 & 1 & 1 & 1 & 2 & 3 & 5 \\
\hline PP2 & 8 & 11 & 7 & 11 & 6 & 9 & 11 & 15 \\
\hline
\end{tabular}

PP1 linguistic competence profile confirms that for the pupil involved in the study expressions of grammatical competence are only possible with alternative communication means also after the intervention. Textual competence is consistent in responses to simple questions. With regards to illocutionary competence, at the beginning of the study the skill to attentively listen to the speaker was detected. After the intervention the results confirm the ability to follow simple instructions. Accordingly, the sociolinguistic competence scores before intervention certify that the pupil responds to his name and presents joy when someone works with him. The scores after intervention confirm that the respondent communicates, is capable to interact with adults, is interested watching others in action, expresses emotional attitude towards different situations.

PP2 linguistic competence profile confirms a relatively comprehensive grammatical competence development in pre-intervention period: the pupil uses 
verbal and alternative means of communication, can answer the questions, e. g., what is your name? how old are you? where do you live? etc. according to the situation, understands and can answer to simple questions, name objects and actions, in conversation uses nouns and verbs. The observation of afterintervention period confirms skill development: skills to show nouns in the picture, expressions of verbs and adjectives, ability to use personal pronoun in the first person, skills to connect words, read the words, form short sentences and find their links to the pictures.

With regards to textual competence this student is able to answer simple questions about his family members and life in the family, create a story about himself and family if leading questions are asked. Before the intervention the pupil was able to clearly tell others about his experiences and picture events related to others (through verbal and alternative means of communication), ask simple questions about a specific situation to others, answer the questions asked by others, was happy to talk to peers, create a story after seeing a picture. After the intervention he was able to repeat accurately short texts, ask questions about the text that was read and was able to recall the scenes of more frequently read stories.

Before the intervention, the illocutionary competence indicators include ability to listen carefully to the speaker or literal reading of the text, the ability to perform simple tasks given by the teacher and to account for their performance, to identify and specify things in the surroundings after the verbal characterization. After the intervention the pupil can recognize and describe the mistakes and correlations in the images, he has skill to involve other pupils in certain activities, ask for help, express wishes or verbally articulate the invitation.

Accordingly, before intervention sociolinguistic competence indicators showed skills to respond to one's name, say the name, surname, age, date of birth, verbally articulate belonging to a specific gender, the names and surnames of other family members and other relatives. The pupil is happy to cooperate with an adult in the communication process, with interest watches and comments on another people's actions, present joy or disliking (using nonverbal means of communication). After the intervention the following aspects were observed: adequate emotional reaction to comical situations, skills to recognize and show emotions in the image, to name emotions and describe the reasons for them, differences are observed in behaviour and communication with familiar and unfamiliar people, skills to use phrases of politeness, gratitude, greeting and parting in familiar situations.

\section{Discussion and conclusions}

Influenced by humanist ideas, modern pedagogy cannot be oriented towards the deficits of human development. On the contrary, its mission is to 
respect the personality development potential and its individual life reality. The most important condition for this approach is to ensure a positive individual's interaction with the material and social environment and to develop support for personal self-determination and self-empowerment efforts.

Exactly such tendencies are identified in this research. The obtained results in general confirm the achievements of language pragmatic competence that is needed for an active and meaningful social life. This statement applies both to the pupils who use expressive verbal speech as well as those who use alternative means of communication. Especially in the cases with limited ability to use verbal language, pupil's skills to listen carefully to the speaker, respond adequately to simple questions and to express the emotional attitude towards the communicative situation are regarded as an achievement.

In addition, the above-described model is designed for characterizing the verbal language competence. However, in its diverse component system it is possible also to include those specific elements that are characteristic to communication of children with severe mental disorders. By contrast, in this context the research aspect of children development of a particular marginal group is considered as the most problematic. In the research process presented in this publication, a number of professionals are involved, and the observation process is implemented over a long period of time in various educational situations. However, even in such circumstances one cannot avoid the subjective presentation of the research results. Therefore, it would be desirable to think about introducing an objective instrument for researching development of this children's group on the national level.

The methodological approach system and thematic planning developed during the research process currently meets the content of Social science syllabus. However, the perfection of communicative competence of pupils with MSMD is topical for all subjects in the context of the educational process. Therefore, consideration should be given to its real functionality is the current Latvian education system in accordance with the curriculum. Probably for ensuring the effective learning process for children with MSMD more appropriate would be on competence formation oriented inter-subject thematic plan.

During the research it was concluded that for development of communicative competence for pupils with MSMD the purposeful collaboration between the class teacher, subject teachers, interest education teachers, boarding school teachers, etc. is of great importance.The implementation of this aspect in qualitative and quantitative ways depends from organization of pedagogical process of each educational establishment.

Parents and if necessary - caregivers are also part of the social network of cooperation. Their awareness and practical contribution is important for further development of skills and abilities, which are acquired in educational process and are at the basis of language pragmatic competence also in after-school 


\section{SOCIETY. INTEGRATION. EDUCATION. Volume III}

environment. For this purpose the accordingly formulated recommendations and training programs should be developed and implemented.

The authors of the article have put forward the Following questions for the discussion and further research: 1) necessity for perfection of methods of diagnosing the special needs and educational process organization for children with MSMD, 2) perfection of cooperation strategies and the forms of work between professionals in educational institutions and extracurricular social environment of pupils for improvement of language pragmatic competence.

\section{References}

Allor, J. H., Mathes, P. G., Cmaplin, T., Cheatham, J. P. (2009). Research-Based Techniques for Teaching Early Reading Skills to Students with Intellectual Disabilities. Education and Training in Developmental Disabilities, 44(3), 356 - 366.

Bachman, L., Palmer, A. (2010). Language Assessment in practice: Developing language assessments and justifying their use in the real world.Oxford: Oxford University Press.

Bachman, L. F., Palmer, A. S. (1996). Language testing in practice. Oxford: Oxford University Press.

Beck, A. R., Stoner, J. B., Bock, S. J., Parton, T. (2008). Comparision of PECS and the use of aVOCA: A Replication. Education and Training in Developmental Disabilities, 43(2), 198-216.

Beecher, L., Childre, A. (2012). Increasing Literacy Skills for Students with Intellectual and Developmental Disabilities: Effects of Integrating Comprehensive Reading Instruction with Sign Language. Education and Training in Developmental Disabilities, 47(4), 487501.

Field, J. (2004). Psycholinguistics. London \& New York: Routledge.

Fulcher, G., Davidson, F. (2007). Language Testing and Assessment. London \& New York: Routledge.

Hudson, M., Browder, D., Wakeman, S. (2013). Helping Students With Moderate and Severe Intellectual Disability Access Grade-Level Text. Teaching Exceptional Children, 45(3), $14-23$.

Lemons, Ch. J., Mrachko, A. A., Kostewicz, D. E., Paterra, M. F. (2012). Effectivness of Decoding and Phonological Awareness Intervention for Children With Down Syndrome. Concil for Exceptional Children, 1(79), 67-90.

Lentes, S., Thiesen, P. (Hrsg.). (2007). Ganzheitliche Sprachförderung. Ein Praxisbuch mit Sprachspielen für Kindergarten, Vorschule und Hort. Berlin: Cornelsne Verlag.

Petry, K., Maes, B. (2007). Description of the Support Needs of People with Profound Multiple Disabilities Using the 2002 AAMR System: An Overview of Literature. Education and Training in Developmental Disabilities, 42(2), 182-189.

Reichert - Garschhammer, E., Kieferle, Ch. (2011). Sprachliche Bildung in Kindertageseinrichtungen. Breisgau: Verlag Herder.

Smith, E. S., Cascella, P. W. (2007). Ratings of Communication Competence by Siblings of Persons with Down Syndrome. Education and Training in Developmental Disabilities, 42(2), 130-143.

Stockall, N. (2011). Cooperative Groups Engaging Elementary Students With Pragmatic Language Impairments. Teaching Exceptional Children, 2 (44), 18-25.

Woods-Groves, S., Hua, Y., Therrien, W. J., Kaldenberg, E. R., Hendrickson, J. M., Lucas, K. G., McAninch, M. J. ( 2014). An Investigation of Strategic Writing Instruction for Post - Secondary Students with Developmental Disabilities. Education and Training in Developmental Disabilities, 49 (2), 248 - 262. 